\title{
Crystallization-induced emission of 1,2-bis(3-methyl-5-(4-alkylphenyl)-2-thienyl)p erfluorocyclopentenes: A mechanical and thermal recording system
}

\section{Tatsumoto Nakahama, Daichi Kitagawa, Hikaru Sotome, Syoji Ito, Hiroshi Miyasaka, Seiya Kobatake}

\begin{tabular}{|c|l|}
\hline \multicolumn{1}{|c|}{ Citation } & Dyes and Pigments, 160; 450-456 \\
\hline Issue Date & 2019 -01 \\
\hline Type & Journal Article \\
\hline Textversion & author \\
\hline Rights & $\begin{array}{l}\text { C } 2018 \text { Elsevier Ltd. This manuscript version is made available under the } \\
\text { CC-BY-NC-ND 4.0 License. https://creativecommons.org/licenses/by-nc-nd/4.0/ } \\
\text { This is the accepted manuscript version. The following manuscript has been accepted } \\
\text { by Dyes and Pigments. The article has been published in final form at } \\
\text { https://doi.org/10.1016/j.dyepig.2018.08.031 }\end{array}$ \\
\hline DOI & $\begin{array}{l}\text { 10.1016/j.dyepig.2018.08.031 } \\
\text { Highlights } \\
\text { fluorescence compared with those in the amorphous phase. } \\
\cdot \text { Fluorescence quantum yields of the crystals decreased with increasing alkyl chain } \\
\text { length. } \\
\cdot \text { The amorphous solid of the diarylethene having methyl group was crystallized after } \\
\text { mechanical scratching followed by heating at 90 }{ }^{\circ} \mathrm{C} \text {. } \\
\cdot \text { Reversible fluorescence recording based on mechanical scratching and heating } \\
\text { induced crystallization was successfully demonstrated. }\end{array}$ \\
\hline
\end{tabular}

\author{
Self-Archiving by Author(s) \\ Placed on: Osaka City University
}

Tatsumoto Nakahama, et al. (2019). Crystallization-induced emission of 1,2-bis(3-methyl-5-(4-alkylphenyl)-2-thienyl)perfluorocyclopentenes: A mechanical and thermal recording system. Dyes and Pigments. 160, 450-456. doi:10.1016/j.dyepig.2018.08.031 


\section{Crystallization-induced emission of 1,2-bis(3-methyl-5-(4-}

\section{alkylphenyl)-2-thienyl)perfluorocyclopentenes: A mechanical and thermal recording system}

Tatsumoto Nakahama ${ }^{\mathrm{a}}$, Daichi Kitagawa ${ }^{\mathrm{a}}$, Hikaru Sotome ${ }^{\mathrm{b}}$, Syoji Ito ${ }^{\mathrm{b}}$, Hiroshi Miyasaka ${ }^{\mathrm{b}}$, Seiya Kobatake, ${ }^{\mathrm{a}, *}$

aDepartment of Applied Chemistry, Graduate School of Engineering, Osaka City University, 33-138 Sugimoto, Sumiyoshi-ku, Osaka 558-8585, Japan

${ }^{b}$ Division of Frontier Materials Science and Center for Promotion of Advanced Interdisciplinary Research, Graduate School of Engineering Science, Osaka University, Toyonaka, Osaka 5608531, Japan

\section{* Corresponding Author}

E-mail address: kobatake@a-chem.eng.osaka-cu.ac.jp (S. Kobatake) 


\section{ORCID}

Tatsumoto Nakahama: 0000-0002-0546-9305

Daichi Kitagawa: 0000-0002-1994-3047

Syoji Ito: 0000-0003-0582-4108

Hiroshi Miyasaka: 0000-0002-6020-6591

Seiya Kobatake: 0000-0002-1526-4629 


\section{ABSTRACT}

Organic luminescent materials have attracted much attention due to potential application to organic optoelectronics. Search for new molecules with high fluorescence quantum yield in solid states is one of the most important tasks in the research field of the organic luminescent materials. Here, we newly synthesized diarylethenes, 1,2-bis(3-methyl-5-(4-alkylphenyl)-2thienyl)perfluorocyclopentenes having methyl, ethyl, $n$-propyl, and $n$-butyl substituents at the $p$ position of phenyl rings, and investigated their fluorescence properties in the solid states. The diarylethenes in the crystalline phase exhibited strong fluorescence with relatively high fluorescence quantum yields $\left(\Phi_{\mathrm{f}}\right)$ of $0.12-0.20$ compared with those in the amorphous phase $\left(\Phi_{\mathrm{f}}\right.$ $=0.064-0.069)$, which indicates that the diarylethenes have crystallization-induced emission (CIE) characteristics. The diarylethene having methyl group as the alkyl chain has the highest $\Phi_{\mathrm{f}}$ value among the diarylethenes that we synthesized in this work. We found that the amorphous solid of the diarylethene having methyl group was crystallized after mechanical scratching followed by heating at $90^{\circ} \mathrm{C}$. We successfully demonstrated reversible fluorescence recording based on CIE characteristics and mechanical scratching and heating induced crystallization.

\section{KEYWORDS}

photochromism; diarylethene; crystal; crystallization-induced emission; fluorescence recording 


\section{Graphical Abstract}
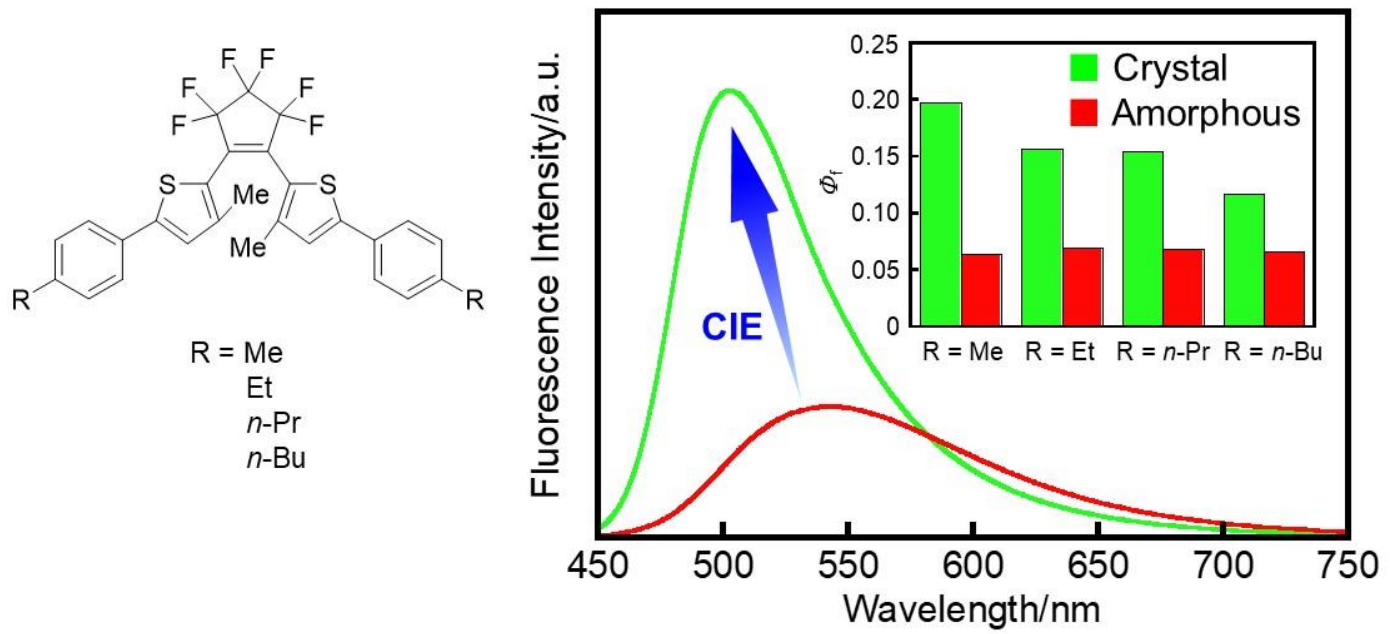


\section{Introduction}

Organic luminescent materials have attracted much attention due to their potential applications, such as organic light-emitting diodes (OLED) [1] and sensory materials [2]. The materials would be used in solid states, such as thin film and crystal, for the applications. However, many luminescent dyes exhibit weak or no emission at high concentration or in the aggregated state even if they exhibit strong emission in dilute solution. The phenomenon is termed as concentration quenching or aggregation caused quenching. To overcome this problem, aggregation-induced emission (AIE) has been widely investigated [3]. The molecules having AIE characteristics exhibit weak or no emission in dilute solution but exhibit strong emission in the aggregated state due to restriction of intramolecular vibrations and rotations. Many researchers have tried to search AIE molecules, which has resulted in discovering of various AIE molecules, such as silole [4,5], tetraphenylethylene [6-8], and cyanostilbene [9-11].

During the studies of the AIE phenomenon, some luminescent dyes which exhibit strong emission in the crystalline phase compared with those in dilute solution and in the amorphous phase were found. The phenomenon is expressed as crystallization-induced emission (CIE) $[12,13]$. Most of the molecules having CIE characteristics exhibit the red-shifted and weak emission in the concentrated amorphous states due to strong intermolecular interactions, such as $\pi-\pi$ stacking by random conformations and disorderly packing in the amorphous states. On the other hand, CIE molecules exhibit the blue-shifted and strong emission in the crystalline phase. They adopt a twisted conformation in the crystal, which prevents strong intermolecular interactions. In addition, there are weak intermolecular interactions such as $\mathrm{C}-\mathrm{H} \ldots \pi$ and $\mathrm{C}-\mathrm{H} \ldots \mathrm{O}$ in the crystal, which reduces the non-radiative decay caused by intramolecular vibrations and rotations [14]. Although 
the CIE phenomenon was first reported in 2005 [13], there are few reports of CIE molecules because many researchers do not compare the emission properties in the amorphous and crystalline phases. The development of CIE characteristics will make it possible to use more stable crystals than metastable amorphous solid to apply to various devices [15]. Thus, the further development of CIE molecules plays an important role in the field of organic luminescent materials.

Photochromic diarylethenes undergo thermally irreversible photoisomerization between a colorless open-ring form and a colored closed-ring form upon alternating irradiation with ultraviolet (UV) and visible light [16]. Some of the diarylethenes exhibit fluorescence in the openor closed-ring forms [17-20]. 1,2-Bis(3-methyl-5-phenyl-2-thienyl)perfluorocyclopentene (1a) exhibits turn-off mode fluorescence switching with a fluorescence quantum yield ( $\left.\Phi_{\mathrm{f}}\right)$ of 0.017 in the open-ring form in $n$-hexane (Scheme 1) [21]. Recently, we found that 1a has two polymorphic forms (crystals 1a- $\boldsymbol{\alpha}$ and 1a- $\beta$ ), which exhibit strong orange and yellow fluorescence ( $\Phi_{\mathrm{f}}=0.52$ and 0.50) [22], respectively, although 1a does not undergo the photocyclization reaction in the solid states. In addition, the open-ring form crystal (crystal 1a') which is produced by the photochemical ring-opening reaction in the crystal of $\mathbf{1 b}$ exhibits green fluorescence $\left(\Phi_{\mathrm{f}}=0.15\right)$ [23]. Thus, 1a has attractive solid-state luminescence properties and can be expected as a new AIE molecular skeleton [24]. The red-shifted fluorescence of $\mathbf{1 a}$ in crystals $\mathbf{1 a -} \boldsymbol{\alpha}$ and $\mathbf{1 a -} \boldsymbol{\beta}$ compared with that in $n$-hexane is ascribed to the intermolecular $\pi-\pi$ interactions between the phenyl rings [23]. Introduction of alkyl substituents to the phenyl rings may modulate the intermolecular $\pi-\pi$ interactions to result in leading to dramatic change in the solid-state luminescence properties.

Here, we have synthesized diarylethenes 2a-5a, 1,2-bis(3-methyl-5-(4-alkylphenyl)-2thienyl)perfluorocyclopentenes having methyl, ethyl, $n$-propyl, and $n$-butyl substituents at $p$ - 
position of the phenyl ring, as shown in Scheme 1, and investigated the photochromic and fluorescence properties in $n$-hexane and in the solid states. In the solid states, $\mathbf{2 a - 5 a}$ exhibited optical properties significantly different from 1a, i.e. different fluorescence color and CIE characteristics depending on alkyl chain length. Moreover, we found that the amorphous solid of 2a crystallizes after mechanical scratching followed by heating to result in strong emission.

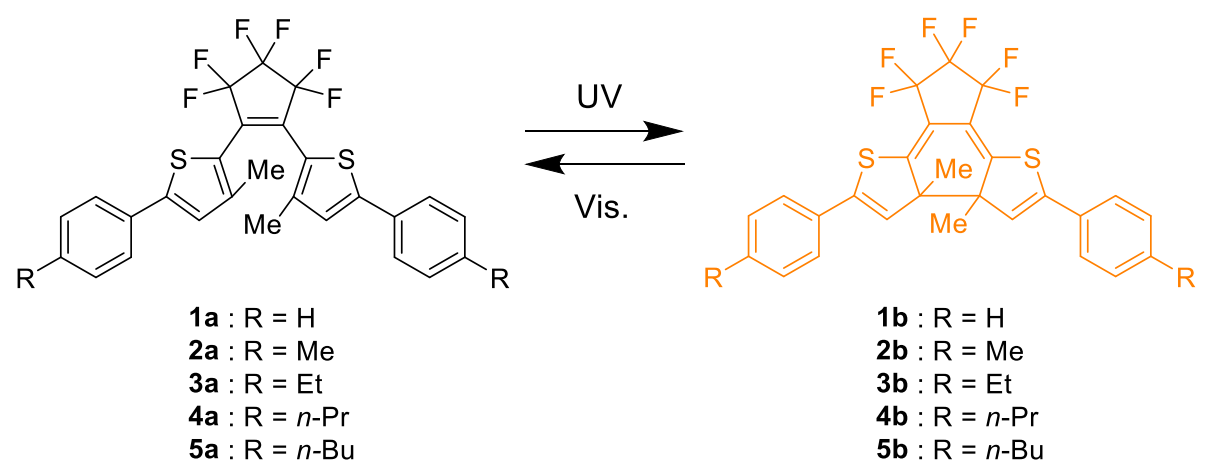

Scheme 1. Molecular structure of diarylethenes used in this work. 


\section{Results and discussion}

\subsection{Photochromic and fluorescence properties in n-hexane}

Diarylethenes $\mathbf{2 a - 5 a}$ underwent reversible photochromic reactions in $n$-hexane upon alternating irradiation with ultraviolet (UV) and visible light. Fig. 1 shows absorption spectra of $\mathbf{2 a}-\mathbf{5 a}$ in $n$-hexane. The optical properties of $\mathbf{2 a - 5 a}$ in $n$-hexane are summarized in Table 1 . For comparison, the optical properties of 1a in $n$-hexane are also shown in Table 1. The absorption maximum wavelengths ( $\lambda_{\mathrm{abs}}$ ) of 2a-5a were observed at 376-377 nm. Upon irradiation with 365 $\mathrm{nm}$ light, new absorption bands appeared around $440 \mathrm{~nm}$. The absorption spectral changes are ascribed to the photocyclization reaction from the open-ring form to the closed-ring form. The photocyclization conversions upon irradiation with $365 \mathrm{~nm}$ were determined to be $91-95 \%$ for $\mathbf{2 a}-$ 5a. Upon irradiation with visible light $(>450 \mathrm{~nm})$, the absorption bands disappeared and the absorption spectra returned to the initial ones. The photocyclization and photocycloreversion quantum yields $\left(\Phi_{\mathrm{o} \rightarrow \mathrm{c}}\right.$ and $\left.\Phi_{\mathrm{c} \rightarrow \mathrm{o}}\right)$ were determined to be $0.10-0.11$ and $0.51-0.53$ for $\mathbf{2 a}-\mathbf{5 a}$, respectively. The $\Phi_{\mathrm{o} \rightarrow \mathrm{c}}$ values decreased slightly in comparison with that of $\mathbf{1 a}\left(\Phi_{\mathrm{o} \rightarrow \mathrm{c}}=0.17\right)$ [21], which indicates that the electron-donating property of alkyl substituents at the $p$-positions of phenyl rings reduces the $\Phi_{\mathrm{o} \rightarrow \mathrm{c}}$ value. 

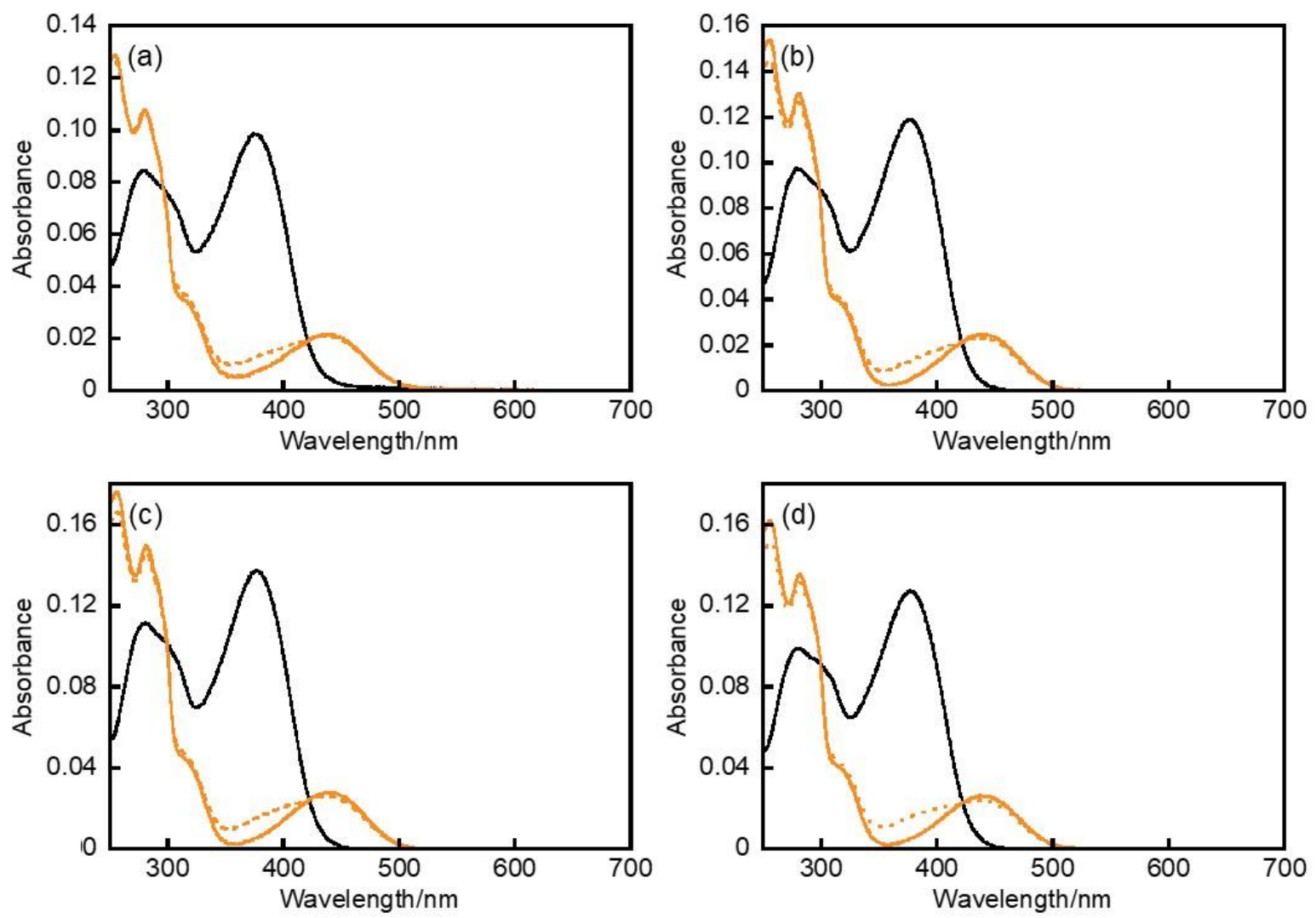

Fig. 1. Absorption spectra of (a) $2 \mathbf{a}\left(3.8 \times 10^{-6} \mathrm{~mol} \mathrm{~L}^{-1}\right)$, (b) $\mathbf{3 a}\left(4.7 \times 10^{-6} \mathrm{~mol} \mathrm{~L}^{-1}\right)$, (c) $\mathbf{4 a}(5.2 \times$ $\left.10^{-6} \mathrm{~mol} \mathrm{~L}^{-1}\right)$, and (d) $5 \mathbf{a}\left(4.8 \times 10^{-6} \mathrm{~mol} \mathrm{~L}^{-1}\right)$ in $n$-hexane: the open-ring isomer (black solid line), the closed-ring isomer (orange solid line), and the photostationary solution upon irradiation with $365 \mathrm{~nm}$ light (orange dashed line). 
Table 1. Optical properties of $\mathbf{1 a - 5 a}$ in $n$-hexane.

\begin{tabular}{|c|c|c|c|c|c|c|c|c|c|c|c|}
\hline \multirow{2}{*}{\multicolumn{3}{|c|}{$\begin{array}{l}\text { Open-ring form } \\
\lambda_{\mathrm{abs}} / \mathrm{nm} \varepsilon / \mathrm{M}^{-1} \mathrm{~cm}^{-1}\end{array}$}} & \multicolumn{2}{|c|}{ Closed-ring form } & \multicolumn{2}{|c|}{ Quantum yield } & \multirow{2}{*}{ Conv. $1 \%$ a) } & \multirow{2}{*}{$\lambda_{\mathrm{flu}} / \mathrm{nm}$} & \multirow{2}{*}{$\Phi_{\mathrm{f}}{ }^{\mathrm{c})}$} & \multirow{2}{*}{$\tau_{1} / \mathrm{ns}^{\mathrm{d})}$} & \multirow{2}{*}{$\tau_{2} / \mathrm{ns}^{\mathrm{d})}$} \\
\hline & & & $\lambda_{\mathrm{abs}} / \mathrm{nm}$ & $/ \mathrm{M}^{-1} \mathrm{~cm}^{-1}$ & $\Phi_{0 \rightarrow c}$ a) & $\Phi_{\mathrm{c} \rightarrow \mathrm{o}}^{\mathrm{b})}$ & & & & & \\
\hline 1a & $370^{\mathrm{e})}$ & $22800^{\mathrm{e})}$ & $438^{\mathrm{e})}$ & $5250^{\mathrm{e})}$ & $0.17^{\mathrm{e})}$ & $0.48^{\mathrm{e})}$ & 95 & $480^{\mathrm{f})}$ & $0.017^{\mathrm{e})}$ & $\begin{array}{c}\left.0.14^{\mathrm{f}}\right) \\
(93.0 \%)\end{array}$ & $\begin{array}{l}\left.0.42^{\mathrm{f}}\right) \\
(7.0 \%)\end{array}$ \\
\hline $2 \mathbf{a}$ & 376 & 25800 & 438 & 5410 & 0.11 & 0.53 & 94 & 485 & 0.056 & $\begin{array}{c}0.20 \\
(98.8 \%)\end{array}$ & $\begin{array}{c}0.47 \\
(1.2 \%)\end{array}$ \\
\hline $3 \mathbf{a}$ & 377 & 25400 & 439 & 5280 & 0.11 & 0.53 & 93 & 486 & 0.059 & $\begin{array}{c}0.22 \\
(98.8 \%)\end{array}$ & $\begin{array}{c}0.43 \\
(1.2 \%)\end{array}$ \\
\hline $4 \mathbf{a}$ & 377 & 26500 & 440 & 5320 & 0.10 & 0.51 & 92 & 486 & 0.059 & $\begin{array}{c}0.22 \\
(99.5 \%)\end{array}$ & $\begin{array}{c}0.55 \\
(0.5 \%)\end{array}$ \\
\hline $5 \mathbf{a}$ & 377 & 26400 & 438 & 5430 & 0.11 & 0.52 & 91 & 487 & 0.058 & $\begin{array}{c}0.22 \\
(91.8 \%)\end{array}$ & $\begin{array}{c}0.35 \\
(8.2 \%)\end{array}$ \\
\hline
\end{tabular}

a) Photocyclization quantum yield upon irradiation at $365 \mathrm{~nm}$. b) Photocycloreversion quantum yield upon irradiation at $440 \mathrm{~nm}$. c) Fluorescence quantum yield excited at $365 \mathrm{~nm}$. d) Fluorescence lifetime excited at $400 \mathrm{~nm}$ and monitored at $500 \mathrm{~nm}$. e) ref. 21. f) ref. 23.

Fig. 2 shows fluorescence spectral changes of $\mathbf{2 a - 5 a}$ in $n$-hexane. Diarylethenes $\mathbf{2 a - 5 a}$ exhibited blue fluorescence with the fluorescence maximum wavelength $\left(\lambda_{\mathrm{flu}}\right)$ of $485-487 \mathrm{~nm}$. The fluorescence quantum yields $\left(\Phi_{\mathrm{f}}\right)$ were determined to be $5-6 \%$ for $\mathbf{2 a}-\mathbf{5 a}$. Upon irradiation with $365 \mathrm{~nm}$, the fluorescence intensities decreased. They returned to the initial ones upon irradiation with visible light. Diarylethenes 2a-5a showed fluorescence lifetimes with two components: $\tau_{1}=$ ca. $200 \mathrm{ps}$ and $\tau_{2}=$ ca. $400 \mathrm{ps}$ (Fig. S1). This indicates that fluorescence consists of two components as well as 1a [23]. No large difference in the fluorescence properties by alkyl chain length was observed in $n$-hexane. 

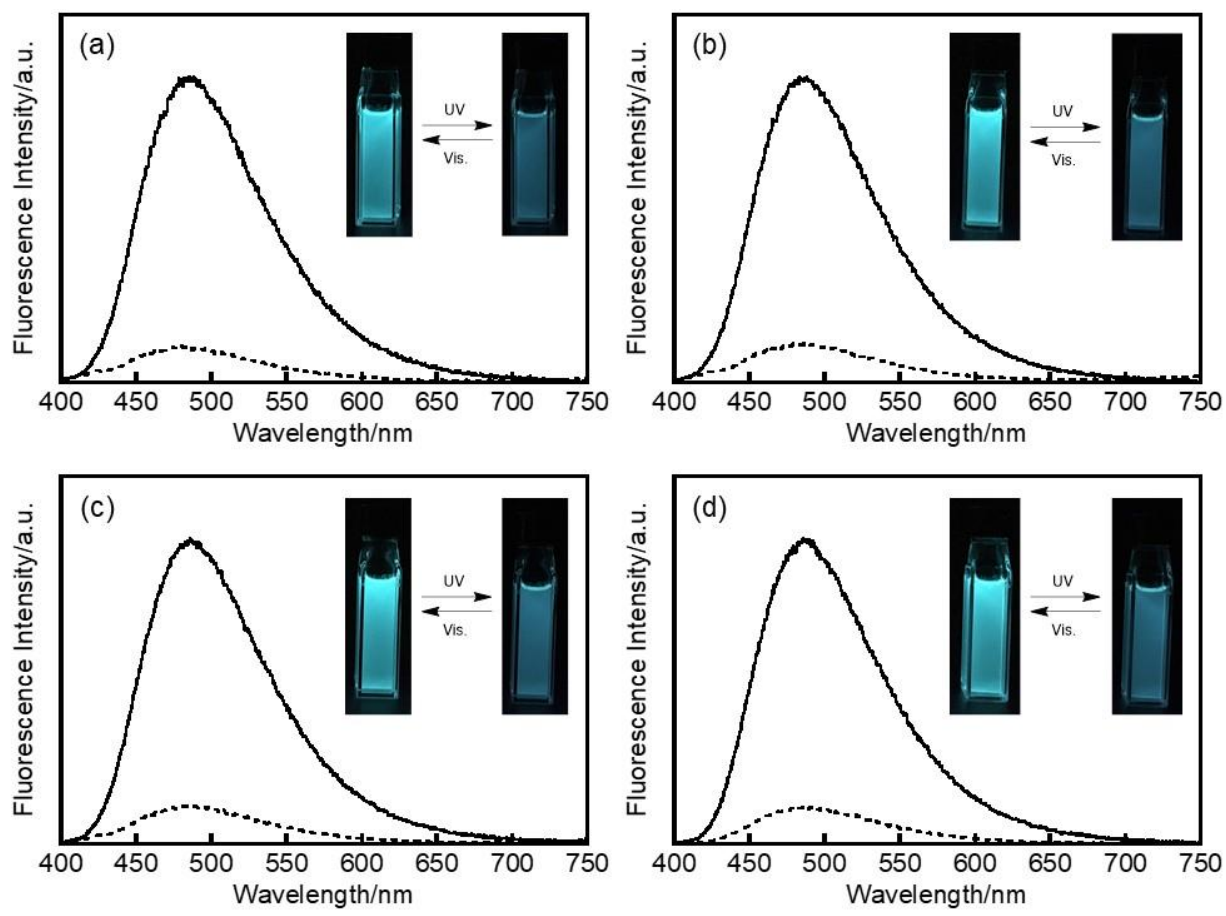

Fig. 2. Fluorescence spectra of (a) $\mathbf{2 a}\left(3.8 \times 10^{-6} \mathrm{~mol} \mathrm{~L}^{-1}\right)$, (b) $\mathbf{3 a}\left(4.7 \times 10^{-6} \mathrm{~mol} \mathrm{~L}^{-1}\right)$, (c) $4 \mathbf{a}(5.2$ $\left.\times 10^{-6} \mathrm{~mol} \mathrm{~L}^{-1}\right)$, and (d) $5 \mathbf{a}\left(4.8 \times 10^{-6} \mathrm{~mol} \mathrm{~L}^{-1}\right)$ in $n$-hexane: the open-ring isomer (solid line) and the photostationary solution upon irradiation with $365 \mathrm{~nm}$ light (dashed line). The fluorescence spectra were recorded upon excitation at $365 \mathrm{~nm}$.

\subsection{Characterization of crystals $\mathbf{2 a}-\mathbf{5 a}$}

Yellow block crystals of $\mathbf{2 a - 5 a}$ were fabricated by recrystallization from $n$-hexane. Single crystal X-ray crystallographic analysis of 2a-5a was performed. The results are summarized in Table S1. The crystal systems are monoclinic for $\mathbf{2 a}, \mathbf{4 a}$, and $\mathbf{5 a}$ and orthorhombic for $\mathbf{3 a}$. The space groups of 2a-5a are $C 2 / c, P b c n, C 2 / c$, and $P 2{ }_{1} / c$, respectively. The crystals have a half molecule for $\mathbf{2 a}$ and $\mathbf{3 a}$, and one molecule for $\mathbf{4} \mathbf{a}$ and $\mathbf{5 a}$ in the asymmetric unit. The diarylethenes exist in the anti-parallel conformation in all crystals. The distances between the reactive carbons 
of the molecules in the crystalline phase are $3.577,3.636,3.613$, and $3.456 \AA$ for $\mathbf{2 a}-\mathbf{5 a}$, respectively, which are sufficiently short for the photocyclization reaction to take place in the crystalline phase [25]. However, all the crystals did not undergo any photocyclization reaction as well as 1a in the crystalline phase although the reason is not clear yet [22].

\subsection{Fluorescence properties in solid states}

Crystals 2a-5a exhibited slight red-shifted fluorescence $\left(\lambda_{\text {flu }}=493-506 \mathrm{~nm}\right)$ compared with those in $n$-hexane, as shown in Fig. 3 . Their fluorescence properties in the solid states are summarized in Table 2 . The fluorescence properties of crystals $\mathbf{2 a - 5 a}$ were significantly different from those of crystals 1a- $\boldsymbol{\alpha}$ and $\mathbf{1 a}-\boldsymbol{\beta}$, which suggests that introduction of the alkyl chains to $p$ position of the phenyl rings affects the fluorescence properties in the crystalline phase. The molecules in crystals 1a- $\boldsymbol{\alpha}$ and $\mathbf{1 a -} \boldsymbol{\beta}$ have face-to-face and edge-to-face $\pi-\pi$ intermolecular interactions between the phenyl rings, which result in the large red-shifted fluorescence in the crystalline phase [22]. On the other hand, the molecules in crystals $\mathbf{2 a - 5 a}$ have no $\pi-\pi$ intermolecular interaction and only van der Waals interaction (Fig. S2-S5). These results indicate that the alkyl chains prevent the formation of the strong $\pi-\pi$ interaction between the phenyl rings to result in only slight red-shifted fluorescence. 

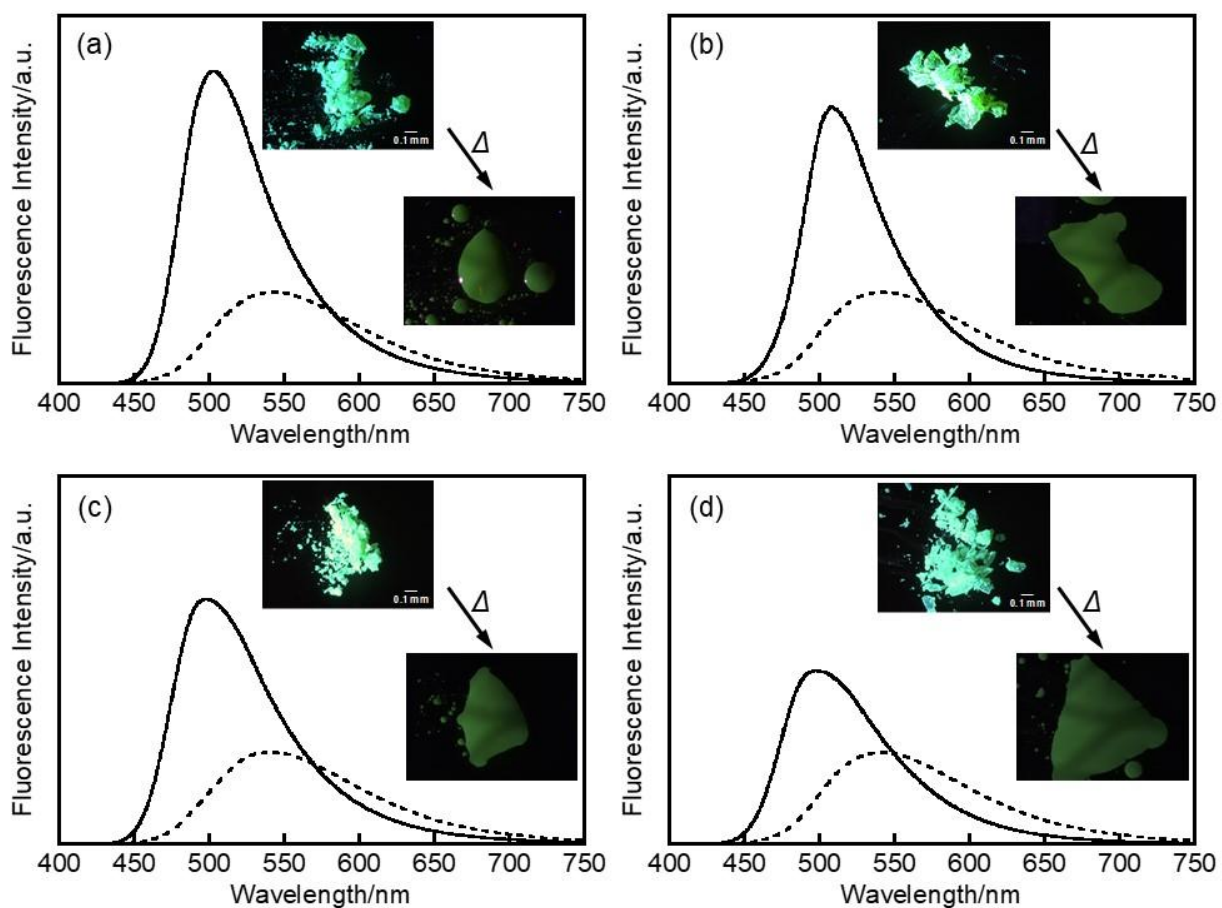

Fig. 3. Fluorescence spectra of (a) 2a, (b) 3a, (c) 4a, and (d) 5a in the crystalline phase (solid line) and in the amorphous phase (dashed line). The fluorescence spectra were recorded upon excitation at $365 \mathrm{~nm}$. 
Table 2. Fluorescence properties of $\mathbf{1 a - 5 a}$ in the solid states.

\begin{tabular}{|c|c|c|c|c|c|c|c|c|c|c|}
\hline & State & $\lambda_{\mathrm{flu}} / \mathrm{nm}$ & $\Phi_{\mathrm{1}}^{\mathrm{a})}$ & $\tau_{1} / \mathrm{ns}$ & $\tau 2 / \mathrm{ns}$ & $\tau_{3} / \mathrm{ns}$ & $\tau_{4} / \mathrm{ns}$ & $\tau_{\text {ave }} / \mathrm{ns}^{\mathrm{b})}$ & $k_{\mathrm{f}} / \mathrm{ns}^{-1}$ & $k_{\mathrm{nr}} / \mathrm{ns}^{-1}$ \\
\hline 1a & Crystal 1a- $\alpha^{c)}$ & 601 & 0.52 & $\begin{array}{c}1.9 \\
(11 \%)\end{array}$ & $\begin{array}{c}4.6 \\
(89 \%)\end{array}$ & - & - & 4.3 & 0.12 & 0.11 \\
\hline 1a & Crystal $\mathbf{1 a}-\boldsymbol{\beta}^{\mathrm{c})}$ & 570 & 0.50 & $\begin{array}{c}1.9 \\
(14 \%)\end{array}$ & $\begin{array}{c}4.5 \\
(86 \%)\end{array}$ & - & - & 4.1 & 0.12 & 0.12 \\
\hline 1a & Crystal 1a' d) & 491 & 0.15 & $\begin{array}{c}0.19 \\
(53 \%)\end{array}$ & $\begin{array}{c}0.40 \\
(46 \%)\end{array}$ & $\begin{array}{c}3.8 \\
(1 \%)\end{array}$ & - & 0.32 & 0.46 & 2.63 \\
\hline $2 a$ & Crystal & 505 & 0.20 & $\begin{array}{c}0.48^{\mathrm{e})} \\
(68.0 \%)\end{array}$ & $\begin{array}{c}0.65^{\mathrm{e})} \\
(32.0 \%)\end{array}$ & - & - & 0.53 & 0.36 & 1.51 \\
\hline $3 a$ & Crystal & 506 & 0.16 & $\begin{array}{l}0.39 \text { e) } \\
(7.3 \%)\end{array}$ & $\begin{array}{c}0.51 \text { e) } \\
(92.7 \%)\end{array}$ & - & - & 0.50 & 0.31 & 1.68 \\
\hline $4 a$ & Crystal & 499 & 0.15 & $\begin{array}{c}0.27^{\mathrm{e})} \\
(24.5 \%)\end{array}$ & $\begin{array}{c}0.40^{\mathrm{e})} \\
(75.5 \%)\end{array}$ & - & - & 0.37 & 0.42 & 2.30 \\
\hline $5 \mathbf{a}$ & Crystal & 493 & 0.12 & $\begin{array}{c}0.31 \text { e) } \\
(83.6 \%)\end{array}$ & $\begin{array}{c}\left.0.40^{\mathrm{e}}\right) \\
(16.4 \%)\end{array}$ & - & - & 0.32 & 0.36 & 2.72 \\
\hline $1 \mathbf{a}^{\mathrm{d})}$ & Amorphous & 596 & 0.20 & $\begin{array}{c}0.30 \\
(46.4 \%)\end{array}$ & $\begin{array}{c}0.84 \\
(25.1 \%)\end{array}$ & $\begin{array}{c}3.1 \\
(21.6 \%)\end{array}$ & $\begin{array}{c}5.6 \\
(6.9 \%)\end{array}$ & 1.41 & 0.14 & 0.57 \\
\hline $2 \mathbf{a}$ & Amorphous & 546 & 0.064 & $\begin{array}{c}0.028^{f)} \\
(42.0 \%)\end{array}$ & $\begin{array}{c}\left.0.28^{\mathrm{f}}\right) \\
(27.4 \%)\end{array}$ & $\begin{array}{c}\left.0.59^{\mathrm{f}}\right) \\
(28.5 \%)\end{array}$ & $\begin{array}{l}1.3^{f)} \\
(2.1 \%)\end{array}$ & 0.28 & 0.22 & 3.30 \\
\hline $3 \mathbf{a}$ & Amorphous & 545 & 0.069 & $\begin{array}{c}0.027^{\mathrm{f}} \\
(45.0 \%)\end{array}$ & $\begin{array}{c}\left.0.25^{\mathrm{f}}\right) \\
(29.6 \%)\end{array}$ & $\begin{array}{c}0.62^{\mathrm{f})} \\
(24.4 \%)\end{array}$ & $\begin{array}{c}2.8^{\mathrm{f}} \\
(1.0 \%)\end{array}$ & 0.27 & 0.26 & 3.51 \\
\hline $4 a$ & Amorphous & 536 & 0.068 & $\begin{array}{l}0.021 \text { f) } \\
(50.6 \%)\end{array}$ & $\begin{array}{c}0.26^{\mathrm{f})} \\
(19.9 \%)\end{array}$ & $\begin{array}{c}0.56 \mathrm{f}) \\
(27.8 \%)\end{array}$ & $\begin{array}{c}1.4^{\mathrm{f})} \\
(1.7 \%)\end{array}$ & 0.24 & 0.28 & 3.85 \\
\hline $5 \mathbf{a}$ & Amorphous & 543 & 0.066 & $\begin{array}{c}\left.0.13^{\mathrm{f}}\right) \\
(34.2 \%)\end{array}$ & $\begin{array}{c}0.46^{\mathrm{f})} \\
(57.6 \%)\end{array}$ & $\begin{array}{l}0.99^{f)} \\
(8.2 \%)\end{array}$ & - & 0.39 & 0.17 & 2.39 \\
\hline
\end{tabular}

The $\Phi_{\mathrm{f}}$ values for crystals $\mathbf{2 a}-\mathbf{5 a}$ were determined to be $0.12-0.20$, which are higher than those in $n$-hexane. To reveal whether the enhanced emission is induced by aggregation or crystallization, the fluorescence properties of $\mathbf{2 a - 5 a}$ in the amorphous solid state were examined. The amorphous solid was prepared by melting crystals followed by cooling to room temperature. The amorphous solids also did not undergo any photocyclization reaction as well as the crystals. The amorphous solids exhibited yellow-green fluorescence with $\lambda_{\text {flu }}$ of ca. $540 \mathrm{~nm}$, which was shifted toward a longer wavelength compared with that of the crystals. It may be due to the intermolecular $\pi-\pi$ interaction [14]. The $\Phi_{\mathrm{f}}$ values were determined to be ca. $6 \%$, which decreased significantly in 
comparison with those in the crystalline phase and were almost the same as those in $n$-hexane. The results indicate that the strong fluorescence of crystals 2a-5a is due to not AIE but CIE.

The dependence of the fluorescence properties on the alkyl chain length is described here. There is no difference in the fluorescence properties of $\mathbf{2 a - 5 a}$ in the amorphous phase. On the other hand, the $\Phi_{\mathrm{f}}$ values for crystals $\mathbf{2 a}-\mathbf{5 a}$ decreased from 0.20 for $\mathbf{2 a}$ having methyl group to 0.12 for 5a having butyl group with increasing alkyl chain length. As shown in Table 2, 2a has the most remarkable CIE characteristics among 2a-5a. To further investigate the fluorescence properties of $\mathbf{2 a}-\mathbf{5 a}$ in the solid states, their fluorescence lifetimes $\left(\tau_{1}\right)$ were measured as shown in Figs. S6 and S7. Amorphous solids of 2a-5a exhibited fluorescence lifetimes with multi components. The faster component of $<1 \mathrm{~ns}$ is attributed to the fluorescence of a single molecule. On the other hand, the slower component of $1-5 \mathrm{~ns}$ is ascribed to the condensed state [23,24]. The average fluorescence lifetimes ( $\left.\tau_{\mathrm{ave}}\right)$ were calculated according to $\tau_{\mathrm{ave}}=\Sigma\left(\tau_{1} \times \%\right)$. Moreover, the radiative rate constants $\left(k_{\mathrm{f}}\right)$ and the non-radiative rate constants $\left(k_{\mathrm{nr}}\right)$ were calculated from $\Phi_{\mathrm{f}}$ and $\tau_{\mathrm{ave}} ; k_{\mathrm{f}}=\Phi_{\mathrm{f}} / \tau_{\mathrm{ave}}$ and $k_{\mathrm{nr}}=\left(1-\Phi_{\mathrm{f}}\right) / \tau_{\mathrm{ave}}$. The $k_{\mathrm{nr}}$ values for the crystals increased from $1.51 \mathrm{~ns}^{-1}$ to $2.72 \mathrm{~ns}^{-1}$ with increasing alkyl chain length. On the other hand, the $k_{\mathrm{f}}$ values for the crystals were hardly changed. These results indicate that the decrease in the $\Phi_{\mathrm{f}}$ values for the crystals with increasing alkyl chain length is due to the increase in the rate constant of the non-radiative decay. As shown in Table S1, the density of the molecules in crystals decreased with increasing alkyl chain length. Therefore, the presence of the longer alkyl chain makes the molecules loosely packed in the crystalline phase, which results in the increase of the non-radiative decay, the decrease of the average fluorescence lifetime, and the low $\Phi_{\mathrm{f}}$ value. 


\subsection{Mechanical scratching and heating induced crystallization}

We have investigated mechanical scratching and heating response for the fluorescence properties of $\mathbf{2 a}$, which has the most remarkable CIE characteristics among $\mathbf{2 a - 5 a}$, in the solid states. In the course of study, we found that the amorphous solid was crystallized with scratching followed by heating at $90{ }^{\circ} \mathrm{C}$. The green fluorescence in the crystalline phase was observed around $500 \mathrm{~nm}$, as shown in Fig. 4, although the amorphous solid after only scratching or heating exhibited the yellow-green fluorescence around $540 \mathrm{~nm}$.

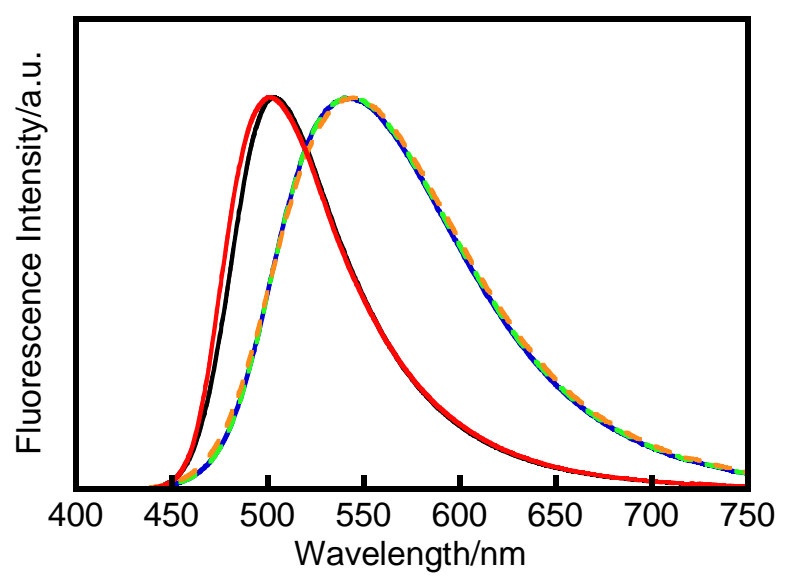

Fig. 4. Normalized fluorescence spectra of $2 \mathbf{a}$ in the crystalline phase (black), in the amorphous phase (blue), in the amorphous phase after only heating at $90{ }^{\circ} \mathrm{C}$ for 10 min (green), in the amorphous phase after only scratching (orange), and in the amorphous phase after scratching and heating at $90^{\circ} \mathrm{C}$ for $10 \mathrm{~min}$ (red).

To investigate the mechanical scratching and heating process in detail, differential scanning calorimetry (DSC) measurement was performed. Fig. 5 shows the DSC traces of $2 \mathbf{a}$ in the 
crystalline phase, in the amorphous phase, and in the amorphous phase after scratching. When the crystal was heated at a rate of $10{ }^{\circ} \mathrm{C} \mathrm{min}^{-1}$, the crystal exhibited a large endothermic behavior due to the crystal melting at $135-150{ }^{\circ} \mathrm{C}$. In addition, the amorphous solid exhibited only a glass transition temperature $\left(T_{\mathrm{g}}\right)$ at $33{ }^{\circ} \mathrm{C}$ (Fig. S8). On the other hand, the amorphous solid after scratching exhibited not only $T_{\mathrm{g}}$ at $33{ }^{\circ} \mathrm{C}$ but also the crystallization with exothermic at $80-100{ }^{\circ} \mathrm{C}$ and the crystal melting with endothermic at $134-150{ }^{\circ} \mathrm{C}$. Thus, the amorphous solid after scratching was crystallized in the region from $80{ }^{\circ} \mathrm{C}$ to $100{ }^{\circ} \mathrm{C}$, although the amorphous solid without scratching was stable to heating.

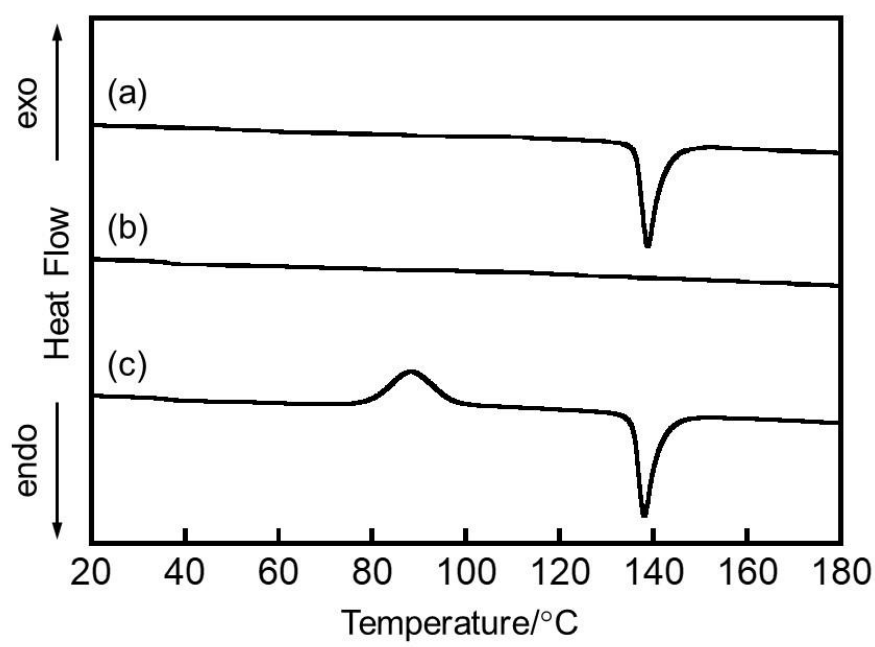

Fig. 5. DSC traces of 2a (a) in the crystalline phase, (b) in the amorphous phase, and (c) in the amorphous phase after scratching. All profiles were measured at a heating rate of $10^{\circ} \mathrm{C} \min ^{-1}$.

Next, powder X-ray diffraction measurement was performed as shown in Fig. 6. The diffraction pattern of crystal 2a was consistent with that calculated from X-ray diffraction of a 
single crystal of 2a. The amorphous solid showed only halo pattern, which did not change even after heating at $90{ }^{\circ} \mathrm{C}$ for $10 \mathrm{~min}$. On the other hand, the amorphous solid after scratching showed small and sharp peaks due to the partial crystallization in addition to the halo pattern. Moreover, the diffraction pattern which is consistent with that calculated for a single crystal of $\mathbf{2 a}$ was observed by heating the amorphous solid with scratching at $90{ }^{\circ} \mathrm{C}$ for $10 \mathrm{~min}$. Thus, the small crystal nuclei were fabricated by scratching and the growth of the crystal nuclei was performed by heating.

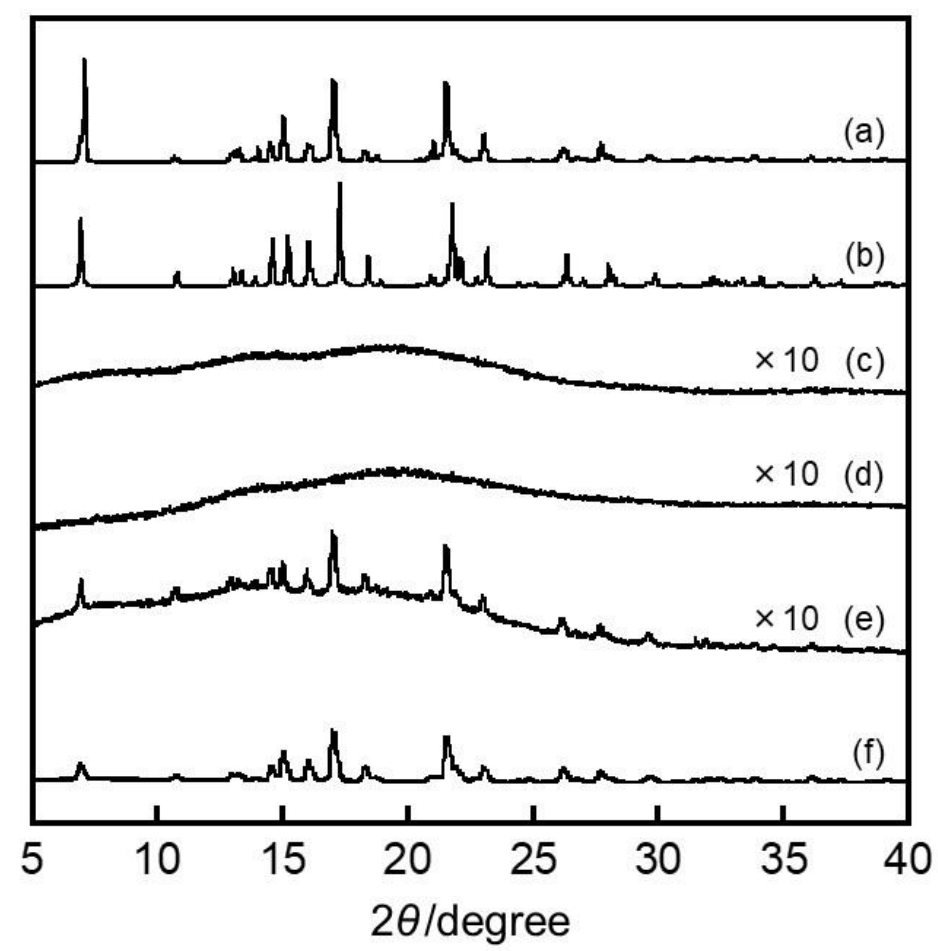

Fig. 6. Powder X-ray diffraction patterns for $\mathbf{2 a}$ at $27^{\circ} \mathrm{C}$ : (a) powder crystals of $\mathbf{2 a}$, (c) amorphous state of $\mathbf{2 a}$, (d) amorphous state of $\mathbf{2 a}$ after heating at $90{ }^{\circ} \mathrm{C}$ for $10 \mathrm{~min}$ followed by cooling, (e) amorphous state of 2a after mechanical scratching, and (f) state of 2a after heating of sample (e) 
at $90{ }^{\circ} \mathrm{C}$ for 10 min followed by cooling. (b) shows the pattern calculated from single crystal $\mathrm{X}$ ray diffraction for $2 \mathbf{a}$ at $-93^{\circ} \mathrm{C}$.

\subsection{Reversible fluorescence recording}

We have tried fluorescence recording based on the mechanical scratching and heating induced crystallization from the amorphous solid. As shown in Fig. 7a, powder crystals of 2a were set on a glass substrate. After that, the crystals were heated at $150{ }^{\circ} \mathrm{C}$ to result in the amorphous solid at room temperature (Fig. 7b). By partly scratching and heating at $90{ }^{\circ} \mathrm{C}$ for $3 \mathrm{~min}$, green fluorescent letter of "D" was clearly written (Fig. 7c). The letter was completely erased by heating at $150{ }^{\circ} \mathrm{C}$ for $30 \mathrm{~s}$. After re-scratching and heating, new letter of "E" was written, and it could be erased again (Fig. 7e and f). In addition, the fluorescence recording returned to its initial state by scratching on whole area and heating. The recorded crystalline part was clearly observed for several hours. As a result, we successfully demonstrated the reversible fluorescence recording based on CIE characteristics and mechanical scratching and heating induced crystallization. Successful fluorescence recording is due to high contrast of fluorescence intensities between the crystalline phase and the amorphous phase, and low fluorescence quantum yield in amorphous solid at the background. Although there are many reports of the crystallization in response to heating or mechanical scratching [26], crystallization induced by both stimuli is rare. The CIE molecules with mechanical scratching and heating induced crystallization ability may be useful for potential applications, such as in sensors and security materials. 

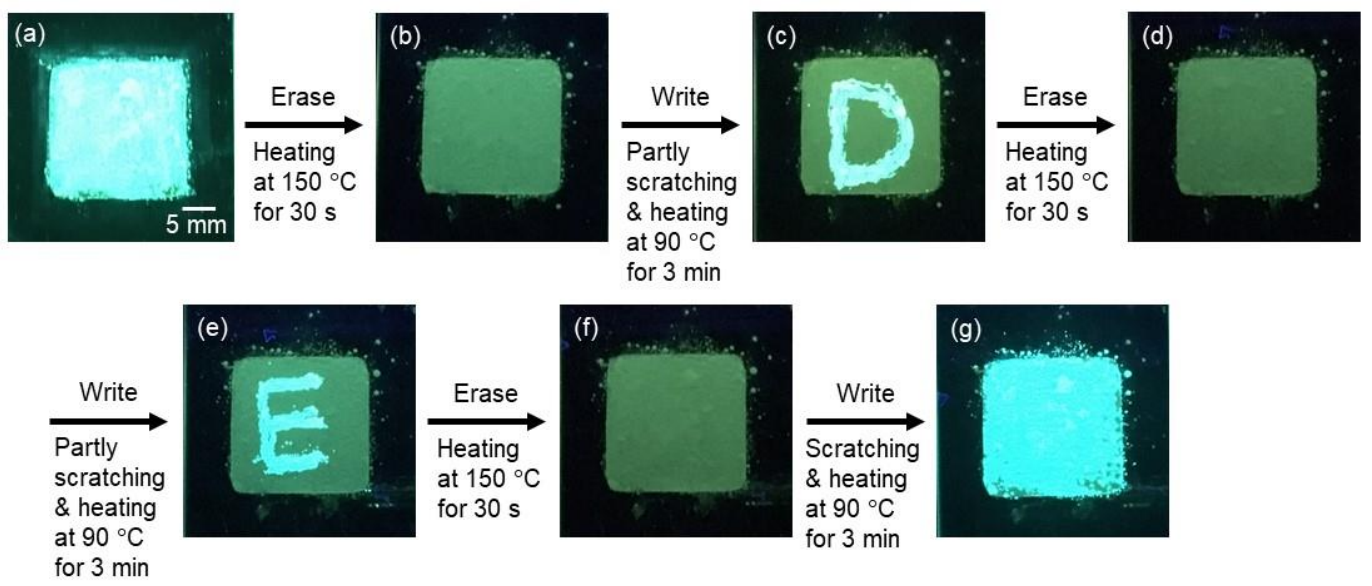

Fig. 7. Reversible fluorescence recording of $\mathbf{2 a}$ observed at room temperature upon excitation at $365 \mathrm{~nm}$ : (a) powder crystals of $\mathbf{2 a},(\mathrm{b}, \mathrm{d}, \mathrm{f})$ amorphous state of $\mathbf{2 a}$ prepared by melting crystals at $150{ }^{\circ} \mathrm{C}$ for $30 \mathrm{~s}$, (c) crystalline recording “ $\mathrm{D}$ ” prepared by partly mechanical scratching and heating at $90{ }^{\circ} \mathrm{C}$ for $3 \mathrm{~min}$, (e) crystalline recording "E" prepared by partly mechanical scratching and heating at $90{ }^{\circ} \mathrm{C}$ for $3 \mathrm{~min},(\mathrm{~g})$ microcrystals of 2a prepared by mechanical scratching on the whole area and heating at $90^{\circ} \mathrm{C}$ for $3 \mathrm{~min}$.

\section{Conclusion}

Diarylethenes having various alkyl chains $(\mathbf{2 a - 5 a )}$ were synthesized and their photochromic and fluorescence properties were investigated in $n$-hexane and in the solid states. Diarylethenes 2a-5a underwent reversible photochromic reactions in $n$-hexane upon alternating irradiation with UV and visible light and exhibited weak fluorescence $\left(\Phi_{\mathrm{f}}=\right.$ ca. 0.05$)$ in their open-ring forms in $n$-hexane. However, 2a-5a in the solid states did not undergo the photocyclization reaction as well as 1a. It was revealed that $\mathbf{2 a}-\mathbf{5 a}$ have CIE characteristics to result in strong fluorescence in the 
crystalline phase compared in $n$-hexane and in the amorphous phase. Crystal 2a had the largest $\Phi_{\mathrm{f}}$ value among crystals $\mathbf{2 a}-\mathbf{5 a}$. In addition, we found that amorphous solid of $\mathbf{2 a}$ was crystallized with mechanical scratching followed by heating. The crystallization is ascribed to the growth of microcrystals produced by scratching. Finally, we successfully demonstrated the reversible fluorescence recording based on the mechanical scratching and heating induced crystallization.

\section{Experimental section}

\subsection{General}

${ }^{1} \mathrm{H}$ NMR spectra were recorded on a Bruker AV-300N spectrometer at $300 \mathrm{MHz}$. Deuterated chloroform $\left(\mathrm{CDCl}_{3}\right)$ was used as the solvent and tetramethylsilane (TMS) as an internal standard, respectively. High resolution mass spectra (HRMS) were obtained on a Bruker FT-ICR/solariX mass spectrometer. The matrix-assisted laser desorption/ionization (MALDI) was used as an ionization technique. trans-2-[3-(4-tert-Butylphenyl)-2-methyl-2-propenylidene]malononitrile (DCTB) was used as matrix. High-performance liquid chromatography (HPLC) was carried out using a Hitachi L-7150/L-2400 HPLC system equipped with a Kanto Chemical Mightysil Si 60 column. Differential scanning calorimetry (DSC) was performed using a Hitachi DSC7000X instrument. Powder X-ray diffraction profiles were recorded on a Rigaku MiniFlex 600 diffractometer employing $\mathrm{CuK}_{\alpha}$ radiation $(\lambda=1.54184 \AA$ ). Single crystal X-ray crystallographic analysis was carried out using a Rigaku AFC/Mercury CCD diffractometer with $\mathrm{MoK}_{\alpha}$ radiation $(\lambda=0.71073 \AA)$ monochromated by graphite. The crystal structures were solved by a direct method using SIR92 and refined by the full-matrix least-squares method on $F^{2}$ with anisotropic 
displacement parameters for non-hydrogen atoms using SHELXL-97. Absorption spectra were measured with a JASCO V-560 absorption spectrophotometer. Photoirradiation in solution was conducted using a 200 W mercury-xenon lamp (Moritex MUV-202) as a light source. Monochromatic light was obtained by passing the light through a monochromator (Jobin Yvon H10 UV) and glass filters. Fluorescence spectra were measured with a JASCO FP-8300 fluorescence spectrophotometer. Fluorescence quantum yields were also determined with a JASCO FP-8300 fluorescence spectrometer equipped with a JASCO ILF-835 integrate sphere.

\subsection{Photochemical reaction}

The photocyclization and cycloreversion quantum yields were determined in $n$-hexane relative to $\mathbf{1 a}{ }^{21}$ whose quantum yield had been previously determined [27]. Photoirradiation was conducted using a $200 \mathrm{~W}$ mercury-xenon lamp (Moritex MUV-202) or a $300 \mathrm{~W}$ xenon lamp (Asahi Spectra MAX-301) as the light source. Monochromatic light was obtained by passing the light through a monochromator (Jobin Yvon H10 UV).

\subsection{Fluorescence lifetime}

Fluorescence lifetimes were measured using a time-correlated single-photon-counting (TCSPC) system. The experimental setup for the TCSPC has been described previously [28]. Briefly, a Ti:sapphire oscillator (Spectra-Physics, Tsunami) was utilized as a pulsed light source. The operation wavelength, pulse width, and repetition rate were set to $800 \mathrm{~nm}, 70 \mathrm{fs}$, and $80 \mathrm{MHz}$, respectively. The fundamentals of the laser were converted to the second harmonics (400 nm) 
using a type I beta barium borate crystal and used to excite the samples. The repetition rate was reduced down to $8 \mathrm{MHz}$ by using an electro-optic modulator (Conoptics, model 350), and the excitation intensity to the samples was typically $17 \mu \mathrm{W}$ at $8 \mathrm{MHz}$. The detection of fluorescence at the magic-angle configuration was attained by utilizing a film polarizer and a Babinet-Soleil compensator. The fluorescence was detected using a photomultiplier tube (Hamamatsu Photonics, R3809U-50) equipped with a preamplifier (Hamamatsu Photonics, C5594) and a TCSPC module

(PicoQuant, PicoHarp 300). For wavelength selection, a monochromator (Princeton Instruments, Acton 2150) was placed in front of the photomultiplier tube. The sample solutions were set in 1 $\mathrm{cm}$ path length of the quartz cells. The typical response time of the system was determined to be 40 ps full width at half maximum by detecting the scattered photons from a colloidal solution.

\subsection{Materials}

Chemicals used for synthesis were commercially available and used without further purification. Diarylethenes $\mathbf{2 a - 5 a}$ were synthesized as shown in Supporting Information.

\section{Notes}

The authors declare no competing financial interest.

\section{Acknowledgments}

This work was partly supported by JSPS KAKENHI Grant Numbers JP26107002, JP26107013 in

Scientific Research on Innovative Areas "Photosynergetics", JP16H06505 in Scientific Research 
on Innovative Areas "Nano-Material Optical-Manipulation", JP16K17896, JP26288009, JP16H03827, and JP15K13625. The authors also thank Nippon Zeon Co., Ltd. for providing octafluorocyclopentene.

\section{Appendix A. Supplementary data}

Supplementary data related to this article can be found at http://dx.doi.org/10.1016/j.dyepig.xxxx. xx.xx.

\section{References}

[1] Uoyama H, Goushi K, Shizu K, Nomura H, Adachi C, Highly efficient organic light-emitting diodes from delayed fluorescence. Nature 2012;492:234-8.

[2] Yagai S, Seki T, Aonuma H, Kawaguchi K, Karatsu T, Okura T, et al. Mechanochromic luminescence based on crystal-to-crystal transformation mediated by a transient amorphous state. Chem Mater 2016;28:234-41.

[3] Hong Y, Lam JWY, Tang BZ. Aggregation-induced emission. Chem Soc Rev 2011;40:536188.

[4] Luo J, Xie Z, Lam JWY, Cheng L, Chen H, Qiu C, et al. Aggregation-induced emission of 1methyl-1,2,3,4,5-pentaphenylsilole. Chem Commun 2001;1740-1.

[5] Tang BZ, Zhan X, Yu G, Lee PPS, Liu Y, Zhu D. Efficient blue emission from siloles. J Mater Chem 2001;11:2974-8. 
[6] Yuan WZ, Chen S, Lam JWY, Deng C, Lu P, Sung HH-Y, et al. Towards high efficiency solid emitters with aggregation-induced emission and electron-transport characteristics. Chem Commun 2011;47:11216-8.

[7] Chan CYK, Zhao Z, Lam JWY, Liu J, Chen S, Lu P, et al. Efficient light emitters in the solid state: synthesis, aggregation-induced emission, electroluminescence, and sensory properties of luminogens with benzene cores and multiple triarylvinyl peripherals. Adv Funct Mater 2012;22:378-89.

[8] Wang W, Lin T, Wang M, Liu T-X, Ren L, Chen D, et al. Aggregation emission properties of oligomers based on tetraphenylethylene. J Phys Chem B 2010;114:5983-8.

[9] An B-K, Kwon S-K, Jung S-D, Park SY. Enhanced emission and its switching in fluorescent organic nanoparticles. J Am Chem Soc 2002;124:14410-5.

[10] An B-K, Lee D-S, Lee J-S, Park Y-S, Song H-S, Park SY. Strongly fluorescent organogel system comprising fibrillar self-assembly of a trifluoromethyl-based cyanostilbene derivative. J Am Chem Soc 2004;126:10232-3.

[11]Yoon S-J, Chung JW, Gierschner J, Kim KS, Choi M-G, Kim D, et al. Multistimuli two-color luminescence switching via different slip-stacking of highly fluorescent molecular sheets. J Am Chem Soc 2010;132:13675-83.

[12]Dong Y, Lam JWY, Qin A, Sun J, Liu J, Li Z, et al. Aggregation-induced and crystallizationenhanced emissions of 1,2-diphenyl-3,4-bis(diphenylmethylene)-1-cyclobutene. Chem Commun 2007;3255-7. 
[13]Dong Y, Lam JWY, Li Z, Qin A, Tong H, Dong Y, et al. Vapochromism of hexaphenylsilole. J Inorg Organomet Polym Mater 2005;15:287-91.

[14] Tang BZ, Qin A. Aggregation-induced emission: fundamentals. John Wiley \& Sons; 2013.

[15]Tong J, Wang YJ, Wang Z, Sun JZ, Tang BZ. Crystallization-induced emission enhancement of a simple tolane-based mesogenic luminogen. J Phys Chem C 2015;119:21875-81.

[16] Irie M, Fukaminato T, Matsuda K, Kobatake S. Photochromism of diarylethene molecules and crystals: memories, switches, and actuators. Chem Rev 2014;114:12174-7.

[17]Fukaminato T, Kobatake S, Kawai T, Irie M. Three-dimensional erasable optical memory using a photochromic diarylethene single crystal as the recording medium. Proc Jpn Acad Ser B 2001;77:30-5.

[18]Fukaminato T, Kawai T, Kobatake S, Irie M. Fluorescence of photochromic 1,2-bis(3-methyl2-thienyl)ethene. J Phys Chem B 2003;107:8372-7.

[19] Morimoto M, Kashihara R, Mutoh K, Kobayashi Y, Abe J, Sotome H, Ito S, Miyasaka H, Irie M. Turn-on mode fluorescence photoswitching of diarylethene single crystals. CrystEngComm 2016;18:7241-8.

[20] Uno K, Niikura H, Morimoto M, Ishibashi Y, Miyasaka H, Irie M. In situ preparation of highly fluorescent dyes upon photoirradiation. J Am Chem Soc 2011;133:13558-64.

[21] Uchida K, Matsuoka T, Kobatake S, Yamaguchi T, Irie M. Substituent effect on the photochromic reactivity of bis(2-thienyl)perfluorocyclopentenes. Tetrahedron 2001;57:455965. 
[22] Kitagawa D, Nakahama T, Mutoh K, Kobayashi Y, Abe J, Sotome H, et al. Polymorphs of a diarylethene that exhibits strong emission and direct visualization of polymorphic phase transition process by fluorescence color change. Dyes Pigm 2017;139:233-8.

[23] Nakahama T, Kitagawa D, Sotome H, Ito S, Miyasaka H, Kobatake S. Solid-state fluorescence behavior induced by photochemical ring-opening reaction of 1,2-bis(3-methyl-5-phenyl-2thienyl)perfluorocyclopentene. Bull Chem Soc Jpn 2018;91:153-7.

[24] Nakahama T, Kitagawa D, Sotome H, Fukaminato T, Ito S, Miyasaka H, et al. Fluorescence on/off switching in nanoparticles consisting of two types of diarylethenes. ACS Omega 2018;3:2374-82.

[25] Kobatake S, Uchida K, Tsuchida E, Irie M. Single-crystalline photochromism of diarylethenes: reactivity-structure relationship. Chem Commun 2002;2804-5.

[26]Chi Z, Zhang X, Xu B, Zhou X, Ma C, Zhang Y, et al. Recent advances in organic mechanofluorochromic materials. Chem Soc Rev 2012;41:3878-96.

[27] Yokoyama Y, Kurita Y. Synthesis and photoreaction of photochromic fulgides. J Synth Org Chem Jpn 1991;49:364-72.

[28] Nagasawa Y, Itoh T, Yasuda M, Ishibashi Y, Ito S, Miyasaka H. Ultrafast charge transfer process of 9,9'-bianthryl in imidazolium ionic liquids. J Phys Chem B 2008;112:15758-65. 